\title{
Statistical modelling of Zimbabwe's international tourist arrivals using both symmetric and asymmetric volatility models
}

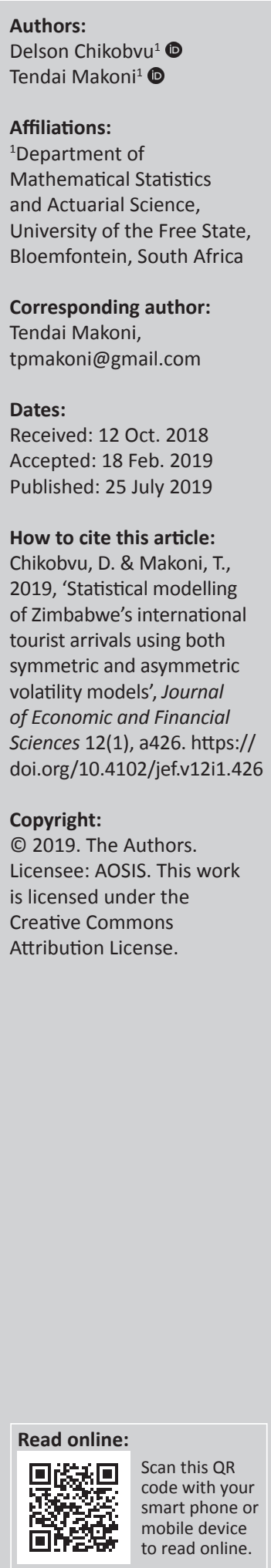

Orientation: Modelling of international tourist arrivals' volatility is vital for marketing, planning, policy formulation and investment purposes among others. Symmetric and asymmetric tourism volatility models for years 2000-2017 were fitted to assess the impact of good and bad news on Zimbabwe's international tourist arrivals' volatility.

Research purpose: In this article, we model Zimbabwe's monthly international tourist arrivals' volatility using both symmetric and asymmetric volatility models and investigate the impact of good and bad news on international tourist arrivals' volatility.

Motivation for the study: Very few, if any, research papers have looked at volatility clustering and the impact of good and bad news on Zimbabwe's international tourist arrivals' volatility. These are important aspects for tourism managers, investors and the government in decisionmaking processes.

Research design, approach and method: The ARMA-GARCH and ARMA-EGARCH models were used to model tourism volatility.

Main findings: The ARMA(1,1)-GARCH(1,1) model under the $t$-distribution (STD) innovations shows unexpected tourism shocks having a strong impact, that persists for significant periods of time, on Zimbabwe's tourist arrivals. The ARMA(1,1)-EGARCH(1,1) model under STD innovations indicated less impact of bad news on future tourism volatility than good news of the same size because the symmetry coefficient gamma $(\gamma)$ is statistically significant and is above zero.

Practical/managerial implications: Tourism volatility models unearth the impact of news on international tourist arrivals' volatility. Good news attracts tourism investors, while bad news discourages tourism investors from investing. Tourism stakeholders, government and investors can use these informative volatility models to the success of the tourism industry in Zimbabwe.

Contribution/value-add: This article highlights the importance of volatility models in the tourism industry.

Keywords: international tourist arrival; GARCH models; EGARCH; TGARCH; APARCH; volatility; persistence.

\section{Introduction}

Zimbabwe's tourism industry plays a significant role in improving the country's economy. The tourism industry contributes immensely to the gross domestic product (GDP) of Zimbabwe, increases foreign currency reserves, creates employment and attracts foreign direct investment (FDI). Zimbabwe is one of the Southern Africa's best and popular tourist arrival destinations. It was accorded the World Best Tourist Destination for 2014 by the General Assembly of European Council on Tourism and Trade (Kelly 2016). It attracts international tourist arrivals from around the world and the tourists play an influential role in the country. The tourism industry brings in much needed foreign currency. International tourist arrivals are the basis of export receipts worldwide (Chang, McAleer \& Slottje 2009).

Zimbabwe is endowed with unique natural resources and ranks among Africa's top tourist destinations (Zimbabwe Parks and Wildlife Management Authority 2017). It has vast tourist attraction sites, including, but not limited to, the Great Zimbabwe Monument and the Victoria Falls Rainforest with its natural environments. The National Parks in Zimbabwe have a variety of 
uncommon plant and animal species. The beautiful sites in Zimbabwe command a significant number of tourist arrivals from across the globe. International tourists are willing to travel overseas and into Zimbabwe in large numbers if their visit and trip can be made safer (Neumayer 2004); hence, the current non-violent environment and political stability prevailing in Zimbabwe need to be capitalised on to attract a large number of tourists. This will accelerate the country's economic growth through tourism proceeds.

Although Zimbabwe is going through a crisis, a lot of opportunities are available in Zimbabwe: tourists from all corners of the world visit the country for business, leisure as well as for recreational purposes. The now peaceful Zimbabwean environment, non-existence of violent episodes, wars or outbreak of deadly diseases such as Ebola, leaves Zimbabwe as a destination of choice. However, dramatic international tourist arrivals' fluctuations are being observed because of political, economic, environmental and social shocks among others. According to Basera (2018), economic recession and political instability had adversely affected Zimbabwe's tourism demand.

It has not always been peaceful in Zimbabwe. It is well known that Zimbabwe experienced economic instability for the past few years, and its impact on the country's tourism industry is still to be assessed. Economic instability and different foreign exchange policies lead to tourism volatility. Sudden fluctuations in international tourist arrivals experienced in Zimbabwe resulted in tourism volatility, which affected the tourism industry particularly in planning purposes and policy formulation. Tourism demand volatility is important for planning and making strategic decisions (Fernando et al. 2013). Understanding the impact of Zimbabwe's international tourist arrival volatility through the use of statistical methods will help the Zimbabwe Tourism Authority (ZTA) to strategically plan its future. The aim of this article is to model Zimbabwe's international tourist arrivals' volatility using symmetric and asymmetric tourism volatility models. Knowing how international tourism demand volatility impacts the economy of Zimbabwe will go a long way in planning and policy formulation and implementation. Tourism growth and volatility management can be achieved through the use of information from adequate modelling of tourism growth and volatility (Divino \& McAleer 2009).

The article is organised as follows. The introduction section is followed by the literature review section, and then the methodology section that presents the methods used. The next section of results presents the findings of the study followed by discussions; finally, the last section concludes and gives recommendations to the tourism stakeholders, investors, government among others.

\section{Literature review}

Fernando (2016) acknowledged the sensitivity of the Sri Lankan tourism industry to tourism shocks such as exchange rate shocks, political violence shocks as well as seasonal variations shocks. International tourist arrivals are very much sensitive to certain shocks such as political violence, war and criminal activities (Fernando et al. 2013). Bad tourism shocks like political instability, terrorism, war and outbreak of deadly diseases among others affect the personal safety of international tourist arrivals.

Zimbabwe's policy environment, namely the economic policy, land reform and indigenisation policy, significantly and negatively affected the domestic tourism (Mutsena \& Kabote 2015). Their effect stretched to international tourists. Muchapondwa and Pimhidzai (2011) identified global income variations, transport cost and specific tourism events as the core determinants of Zimbabwe's tourism demand. The identified factors significantly contribute to international tourism volatility. Page and Lumsdon (2004) echoed the same sentiment that transport system impacts on tourists' travel, holiday type and transport mode. Travelling costs determine tourist's destination, transport mode and travelling arrangements. A global income variation determines the type of food, accommodation and places to be visited by the tourists as well as the number of days to be spent in preferred tourist destination areas. It also plays a major role in destination selection criteria as well as the types and numbers of tourism activities to attend.

Kabote, Mashiri and Vengesayi (2014) noted that Zimbabwe's domestic tourism is highly price sensitive as a result of the country's pricing policies. The pricing policies also result in international tourist arrivals' volatility. For the Kariba tourism resort in Zimbabwe, Basera (2018) found a relationship between tourism demand and tourism marketing. Marketing Zimbabwe's tourism resorts positively influences the success of the tourism industry. These effective tourism marketing strategies affect both domestic and international tourists and result in tourism variations. International tourism volatility modelling will help in devising effective marketing strategies that will reduce the volatility.

Tourism volatility clustering is normally evident in tourism series where large tourism fluctuations will be followed by large tourism fluctuations, while small tourism fluctuations will be followed by small tourism fluctuations. Various models have the ability to capture and explain tourism volatility. Some of these models include the autoregressive conditional heteroscedasticity (ARCH) models, autoregressive moving average-generalised autoregressive conditional heteroscedasticity (ARMA-GARCH), exponential GARCH (EGARCH), threshold GARCH (TGARCH) and asymmetric power ARCH (APARCH) models. The asymmetric models (EGARCH, TGARCH and APARCH) are capable of capturing the leverage effects and asymmetric effects in tourism for which the ordinary GARCH fails to account. According to Karlsson (2002), the EGARCH models allow both the negative and positive shocks to impact differently on the tourism volatility. Various researches highlighted that positive and negative tourism shocks impact differently 
on the tourism industry. Angabini and Wasiuzzaman (2011) noted the greater increase in volatility as a result of bad news when compared to good news.

Fernando et al. (2013) adopted the GARCH(1,1) model and noticed large volatility in Sri Lanka's monthly tourist arrivals. Priyangika, Pallawala and Sooriyaarachchi (2016) fitted an $\mathrm{ARCH}(1)$ with optional lags and the model was used to forecast future Sri Lankan tourist arrivals. In Taiwan, Chang et al. (2009) fitted the GARCH(1,1), GJR $(1,1)$ and $\operatorname{EGARCH}(1,1)$ using daily tourism data and noted sensitive tourism volatility estimates with sensible interpretations. According to Divino and McAleer (2009), daily Peru tourism data fitted well to the estimated symmetric and asymmetric conditional volatility models. Long- and short-run persistence of shocks to international tourist arrivals was observed. Shareef and McAleer (2015) estimated statistically adequate volatility models for the six Small Islands Tourism Economies (SITEs), namely Cyprus, Fiji, Dominica, Maldives, Barbados and Seychelles. The estimated volatility models are useful to both public and private sector tourism managers.

Hoti, Leon and McAleer (2004) used a GARCH(1,1) model to describe international tourism volatility for the Canary Islands. The model produced accurate volatility measures. Chhorn and Chaiboonsri (2018) noted both short- and longrun persistent tourism shocks from the GARCH(1,1) model estimated using Cambodia tourism data. Neupane, Shrestha and Upadhyaya (2012) fitted the GARCH, GARCH-GJR and EGARCH with exogenous ARMA terms to Nepal's monthly international tourism data. Statistically significant long-run volatility persistence was noted. Amendment of Nepal's tourism policy was recommended as a result of the uncertainty associated with international tourist arrivals that was noted. All the above-mentioned authors highlighted the importance of modelling tourism volatility using both symmetric and asymmetric volatility models. This article will make use of both the symmetric and asymmetric volatility models in the case of Zimbabwe.

\section{Methodology}

A time series approach in the form of symmetric and asymmetric volatility models was adopted. The $\mathrm{ARCH}$, GARCH,ARMA-GARCH, EGARCH, TGARCH and APARCH models were noted as the commonly used symmetric and asymmetric volatility models.

\section{Autoregressive moving average models}

A combination of $\operatorname{AR}(p)$ and $\operatorname{MA}(q)$ models gives an $\operatorname{ARMA}(p, q)$ model and suits univariate time series (Adhikari \& Agrawal 2013). The model can be represented as:

$Y_{t}=\mu+\sum_{i=1}^{p} \phi_{i} Y_{t-i}+\sum_{j=1}^{q} \theta_{j} \varepsilon_{t-j}+\varepsilon_{t}$

Model parameters are represented by $\theta$ and $\phi$ while $p$ and $q$ are the autoregressive and moving average terms, respectively.
The monthly international tourist arrival series is denoted by $Y_{t^{\prime}}$ whereas $\mu$ and $\varepsilon_{t}$ are the constant and error terms, respectively.

\section{Autoregressive conditional heteroscedasticity effects}

The existence of autocorrelation on squared series of residuals is referred to as ARCH effects in the context of this article. When time series data are stationary, it is also important to test for an $\mathrm{ARCH}$ effect, which is the testing of the dynamics of conditional variance. The Breusch-Godfrey Lagrange Multiplier (LM) is used in testing the ARCH effect prior to GARCH model estimation.

\section{Autoregressive conditional heteroscedasticity model}

The ARCH model was proposed by Engle (1982) to describe conditional variance in time series data and is fitted if the time series data prove to have ARCH effects. Under the ARCH model, the variance is forecasted as a moving average of past error terms (Engle, Focardi \& Fabozzi 2012). Considering a serially uncorrelated tourism return series that exhibits excess autocorrelated squares, we can have:

$\varepsilon_{t}=\sigma_{t} z_{t^{\prime}} \quad z_{t} \sim N(0,1)$

[Eqn 2]

where volatility $\left(\sigma_{t}^{2}\right)$ changes over time. Furthermore, the volatility, $\sigma_{t}^{2}$, is assumed to be given by:

$\sigma_{t}^{2}=\alpha_{0}+\alpha_{1} \varepsilon_{t-1}^{2}+\cdots+\alpha_{q} \varepsilon_{t-q}^{2}=\alpha_{0}+\sum_{i=1}^{q} \alpha_{i} \varepsilon_{t-i}^{2}$

[Eqn 3]

where $\alpha_{0}>0$ and $\alpha_{i} \geq 0$ so that $\sigma_{t}^{2}$ is positive.

Alberg, Shalit and Yosef (2008) noted that the dynamic behaviour of conditional variance can be captured well by a high ARCH order. This challenge prompted the development of the generalised ARCH (GARCH) model by Bollerslev in 1986. According to Alberg et al. (2008), the GARCH model is based on an infinite ARCH specification, hence can reduce parameters to be estimated to two.

\section{Generalised autoregressive conditional heteroscedasticity models}

Bollerslev (1986) proposed the $\operatorname{GARCH}(p, q)$ model which is an econometric term that describes volatility estimation approach using volatile series. The $\operatorname{GARCH}(p, q)$ model is fitted under three conditional error distributional assumptions, namely normal distribution (Norm), $t$-distribution (STD) and the generalised error distribution (GED). The models can be expressed as:

$\sigma_{t}^{2}=\omega+\beta \sigma_{t-1}^{2}+\alpha \varepsilon_{t-1}^{2}$

[Eqn 4]

with $\sigma_{t}^{2}$ being the variance, $\omega>0, \alpha \geq 0, \beta \geq 0$ and $(\alpha+\beta<1)$. $\operatorname{An} \operatorname{ARMA}(p, q)$ process, denoted by $Y$, with a GARCH noise 
used to model linear dependency on the series and $\mathrm{ARCH}$ effect on residuals can be expressed as:

$Y_{t}=\mu+\sum_{j=1}^{q} \beta_{j} \varepsilon_{t-j}+\sum_{i=1}^{p} \alpha_{j} Y_{t-i}+\varepsilon_{t}$

$\varepsilon_{t}=Z_{t} \sigma_{t}, Z_{t} \sim$ i.i.d $\mathrm{N}(0,1)$

[Eqn 6]

$\sigma_{t}^{2}=\alpha_{0}+\alpha_{1} \varepsilon_{t-1}^{2}+\alpha_{2} \varepsilon_{t-2}^{2}+\cdots+\alpha_{p} \varepsilon_{t-p}^{2}+\beta_{1} \sigma_{t-1}^{2}+\beta_{2} \sigma_{t-2}^{2}+\cdots+\beta_{q} \sigma_{t-q}^{2}$

[Eqn 7]

where $\alpha_{i}, \beta_{j}$ and $\mu$ are model parameters and $\varepsilon_{t}$ are the model residuals.

With GARCH models, no theoretical explanation of volatility is provided (Omari, Mwita \& Waititu 2017), and no volatility information flows is known (Tsay 2010). In addition, the GARCH model is not capable of handling skewed time series as done by the EGARCH (Omari et al. 2017) and does not fit well to thick tails in financial time series (Alberg et al. 2008). This challenge can be extended to tourism series as Chang and McAleer (2009) reported that international tourist arrivals estimates resemble those of financial time series data during modelling daily tourist arrivals exchange rates volatility for Korea and Taiwan. Lama et al. (2015) acknowledged the failure to deal with the positivity or negativity of shocks of the GARCH model as done by the EGARCH model.

Furthermore, the ARCH and GARCH models use symmetric distributions to capture volatility and not the leverage effect (Alberg et al. 2008). The failure to capture leverage effect by the $\mathrm{ARCH}$ and GARCH models necessitated the introduction of the EGARCH model, GJR-GARCH model and the APARCH model by Nelson (1991), Glosten, Jagannathan and Runkle (1993) and Ding, Granger and Engle (1993), respectively.

\section{Exponential generalised autoregressive conditional heteroscedasticity model}

The EGARCH model was developed by Nelson in 1991. The model determines the asymmetric effect on conditional volatility:

$\log \left(\sigma_{t}^{2}\right)=\omega+\beta \log \left(\sigma_{t-1}^{2}\right)+\alpha\left\{\left|\frac{\varepsilon_{t-1}}{\sigma_{t-1}}-\sqrt{\frac{2}{\pi}}\right|\right\}-\gamma \frac{\varepsilon_{t-1}}{\sigma_{t-1}} \quad$ [Eqn 8]

where $\gamma$ is the symmetry coefficient that generates the leverage effects. Bad news will impact more on future volatility than good news of the same size; if $\gamma<0$, and if $\gamma \neq 0$ then the asymmetric impact will exist. The symmetric effect of the model is represented by $\alpha$, while $\beta$ measures the persistence level.

\section{The Glosten, Jagannathan and Runkle-generalised autoregressive conditional heteroscedasticity model}

The Glosten, Jagannathan and Runkle-GARCH (GJRGARCH) model is an asymmetric model and was developed by Glosten et al. in 1992. It has the capacity of capturing the positive and negative impacts of shocks like the EGARCH. The GJR-GARCH $(1,1)$ model is given as:

$\sigma_{t}^{2}=\omega+\beta \sigma_{t-1}^{2}+\left(\alpha+\gamma I\left(\eta_{t-1}\right)\right) \varepsilon_{t-1}^{2}$

where $\gamma$ is the coefficient capable of capturing asymmetric effects in the data, $\alpha$ is the coefficient representing the positive short-run impact of shocks and $(\alpha+\gamma)$ represents the negative short-run impact of shocks. The coefficients satisfy the following conditions: $(\alpha+\gamma) \geq 0, \alpha, \beta \geq 0, \omega>0$. The indicator variable $I\left(\eta_{t}\right)\left(\eta_{t}\right.$ is the leverage parameter) differentiates positive and negative shocks of equal magnitude and are defined by:

$I\left(\eta_{t}\right)=\left\{\begin{array}{l}1, \varepsilon_{t}<0 \\ 0, \varepsilon_{t} \geq 0\end{array}\right.$

[Eqn 10]

Short-run and long-run persistence of volatility is given by $\alpha+0.5 \gamma$ and $\alpha+0.5 \gamma+\beta$, respectively, if $\eta_{t}$ follows a symmetric distribution. According to Ling and McAleer (2002), $\alpha+0.5 \gamma$ $+\beta<1$ is the necessary condition for the existence of the second moment for GJR(1,1). McAleer, Chan and Marinova (2007) proved that the log-moment condition for GJR $(1,1)$ is given by:

$E\left(\ln \left[\left(\alpha+\gamma I\left(\eta_{t}\right)\right) \eta_{t}^{2}+\beta\right]\right)<0$

[Eqn 11]

\section{The threshold generalised autoregressive conditional heteroscedasticity model}

The TGARCH model developed by Zakoian (1994) is similar to the GJR-GARCH model. It is an asymmetric model of the GARCH family of models and decomposes the volatility components and examines the asymmetric effect of shocks.

$\sigma_{t}^{2}=\omega+\beta \sigma_{t-1}^{2}+\left(\alpha+\gamma d_{t-1}\right) \varepsilon_{t-1}^{2}$

where $d_{t-1}$ is a dummy variable which can either be 0 or 1 . When $\varepsilon_{t-1}^{2}<0$ and $\varepsilon_{t-1}^{2} \geq 0$, then $d_{t-1}=1$ and $d_{t-1}=0$, respectively. Good news (when $\varepsilon_{t-1}^{2} \geq 0$ ) and bad news $\left(\varepsilon_{t-1}^{2}<0\right.$ ) have different impact on volatility. Good and bad news have an impact of $\alpha$ and $(\alpha+\gamma)$, respectively. Volatility increases because of bad news, and this happens only if $\gamma>0$, and this implies the existence of leverage effects. News impact is asymmetric when $\gamma \neq 0$.

\section{The asymmetric power autoregressive conditional heteroscedasticity}

Ding et al. (1993) introduced the APARCH model as a way of coming up with a model that accommodates fat tails and excess kurtosis and explains leverage effects. The model's structure is as follows:

$\sigma_{t}^{\delta}=\omega+\sum_{j=1}^{p} \beta_{j}\left(\sigma_{t-j}\right)^{\delta}+\sum_{i=1}^{q} \alpha_{i}\left(\left|\varepsilon_{t-i}\right|-\gamma_{i} \varepsilon_{t-i}\right)^{\delta}+\varepsilon_{t}$

[Eqn 13]

where $\omega, \alpha_{i}, \beta_{i}, \gamma_{i}$, and $\delta$ are the model parameters to be estimated. Leverage effect is reflected by $\delta$. Negative information impacts more heavily than positive information on the tourism volatility when $\gamma_{i}$ is positive. The APARCH 
model operates under the conditions, $\omega>0, \alpha_{i} \geq 0, i=1,2, \ldots$, $q, \beta_{j} \geq 0, j=1,2, \ldots, p$ and $0 \leq \sum_{j=1}^{p} \beta_{j}+\sum_{i=1}^{q} \alpha_{i}+\leq 1$. According to Rodriguez (2017), long memory parameter estimation is possible through the use of the APARCH model and the model also allows the modelling of fat tails, like those exhibited by the tourism series.

\section{Results}

\section{Data and descriptive statistics}

The data set consists of monthly international tourist arrivals from 01 January 2000 to 30 June 2017, giving 210 observations. The data are obtained from the ZTA, a state organisation that deals with tourism issues. The logarithm of the monthly international tourist arrivals $(L Y)$ and the growth rates (logdifference) $(L D Y)$ of the monthly international tourist arrivals are calculated and descriptive statistics are summarised in Table 1 . The data are log transformed to make them stationary.

The descriptive statistics displayed in Table 1 indicate 12.027 as the mean of $L Y$, while 9.649 and 13.094 are the minimum and maximum values, respectively, for the same data. The mean, minimum and maximum values of $L D Y$, are -0.001 , -1.421 and 1.564, respectively. The skewness values of $L Y_{t}$ and $L D Y_{t}(-1.860$ and -0.111$)$ suggest negative skewness of the data, and kurtosis values of $L Y_{t}$ and $L D Y_{t}$ (12.781 and 6.342) indicate non-normality of the data sets. The plots of $L Y_{t}$ and $L D Y_{t}$ are displayed in Figure 1 together with their volatility. The raw data are analysed, and a time series plot is shown in Figure 2.

The series are found to be non-stationary as indicated by various fluctuations exhibited in Figure 2. The lowest and

TABLE 1: Descriptive statistics of $L Y_{t}$ and $L D Y_{t}$.

\begin{tabular}{lllllllll}
\hline Series & Minimum & Maximum & Median & Mean & $\begin{array}{c}\text { Standard } \\
\text { deviation }\end{array}$ & Skewness & Kurtosis \\
\hline$L Y_{t}$ & 9.649 & 13.094 & 12.027 & 11.992 & 0.387 & -1.860 & 12.781 \\
$L D Y_{t}$ & -1.421 & 1.564 & -0.010 & -0.001 & 0.389 & -0.111 & 6.343 \\
\hline
\end{tabular}

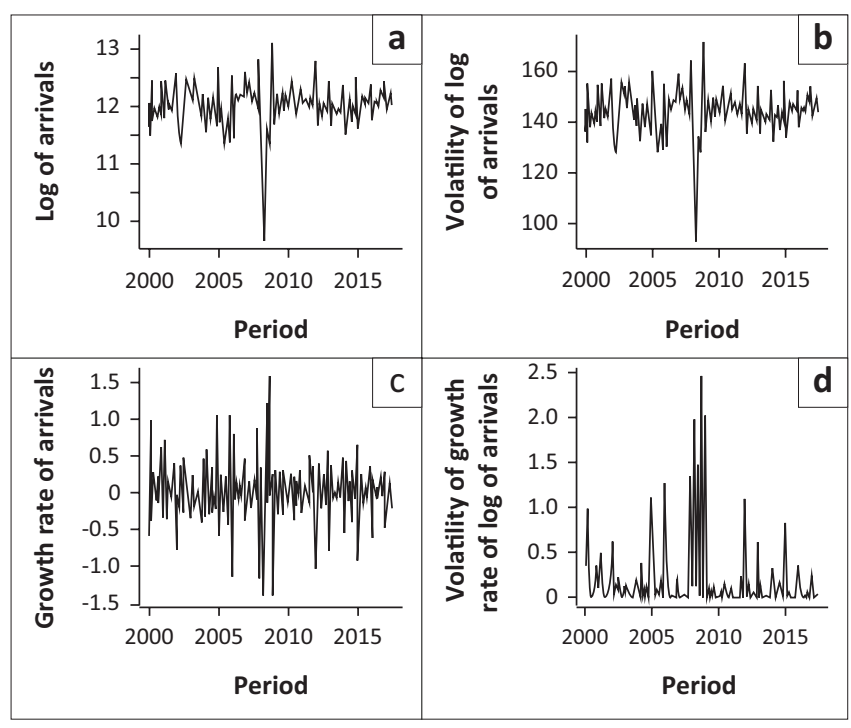

FIGURE 1: Log of international tourist arrivals (a), volatility of log of internationa tourist arrivals (b) growth rate of international tourist arrivals (c) and volatility of growth rate of international tourist arrivals (d). highest international tourist arrivals were reached around 2008 and 2009, respectively. The series indicate steady fluctuations between 2006 and 2017 except around 2008 as exhibited in Figure 2. During 2008, Zimbabwe faced a lot of challenges including political and economic instability. The increase in international tourist arrival in 2009 could partly be attributed to the formation of government of national unity and the introduction of multiple currencies which reduced the shrinking of the Zimbabwe economy at that point in time.

Volatility persistence was witnessed on all the series. Furthermore, an extreme value was observed in the logarithm of the monthly international arrivals and their volatility around the year 2008. This might be a result of the presidential elections that were held during the year 2008. Both the logarithm of the monthly and growth rates of international tourist arrivals seem to depict a stationary time series. The extreme observation in the logarithm of international tourist arrivals was mirrored in the growth rates. The augmented Dickey-Fuller (ADF) test was conducted on both $L Y_{t}$ and $L D Y_{t}$.

Table 2 indicated that both $L Y_{t}$ and $L D Y_{t}$ do not have unit roots and this was supported by the ADF test statistics of $-8.330(p=0.01)$ and $-20.247(p=0.01)$, respectively.

\section{Parameter estimation}

As all the data sets are stationary and exhibit volatility clustering, various symmetric and asymmetric models capable of capturing and explaining volatility are fitted. Model parameters are estimated using the maximum likelihood estimation (MLE) method.

\section{Estimated volatility models}

Several volatility models (ARMA-GARCH, EGARCH, TGARCH and APARCH models) are estimated using the logarithm of international tourist arrivals under normal, student's $t$ and GED innovations. The $t$-distribution is good at heavy tails according to Bollerslev et al. (1987); hence, it is preferred in this study. During modelling exchange rate volatility using APARCH models, Ogutu, Canhanga and Biganda (2018) acknowledged the superiority of student's $t$-distribution over other error distributions such as the normal

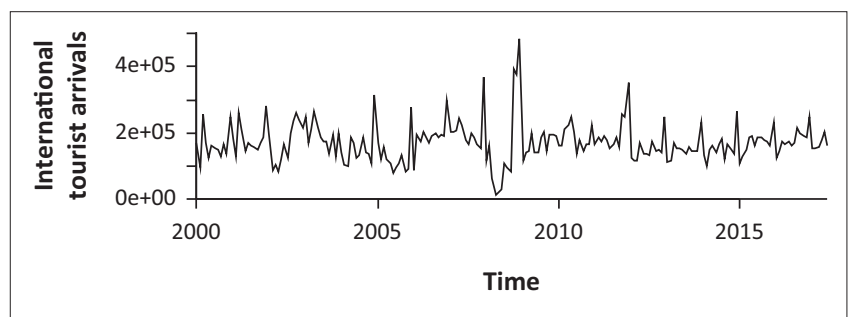

FIGURE 2: International tourist arrivals series.

TABLE 2: Augmented Dickey-Fuller test.

\begin{tabular}{lccc}
\hline Series & ADF test statistics & Lag order & $\boldsymbol{p}$ \\
\hline$L Y_{t}$ & -8.330 & 12 & 0.01 \\
$L D Y_{t}$ & -20.247 & 12 & 0.01 \\
\hline
\end{tabular}

ADF, augmented Dickey-Fuller. 
in modelling similar data. The preferred model is selected based on Akaike information criterion (AIC) and Bayesian information criterion (BIC). The ARMA(1,1)-GARCH $(1,1)$ model was fitted first and results are summarised in Figure 3.

All the model parameters in Figure 3 are statistically significant for all the specified models, and the basic model conditions are satisfied $(\alpha+\beta<1)$. The sum $(\alpha+\beta)$ is close to 1 indicating that unexpected tourism shocks will impact strongly and persist for a significant periods of time on Zimbabwe's tourism demand. Jegajeevan (2012), Chang and McAleer (2009) and Lorde and Moore (2008) noted similar findings of a high persistent level that lasted for a long period in Sri Lanka, Taiwan and Barbados, respectively. Furthermore, the goodness of fit (AIC and BIC) is slightly better for the ARMA $(1,1)-G A R C H(1,1)$ model under STD innovations. All the models passed the white noise test as indicated by the Ljung-Box test statistic values which are associated with the $p$-values of both squared residuals and standardised squared residuals, at all lags (Lag 1, Lag 2 and Lag 4) which are all above 0.05 implying no presence of autocorrelation into the standardised residuals or squared standardised residuals. The ARCH LM test statistic values at Lag 3, Lag 5 and Lag 7 show no dependencies in the standardised series because of the corresponding $p$-values that are above 0.05 .

The Jarque-Bera test for normality was conducted to check the normality of the standardised residuals from the
$\operatorname{ARMA}(1,1)-\mathrm{GARCH}(1,1)$ type modes before fitting asymmetrical models.

Table 3 results suggested the rejection of the null hypothesis of normality of the standardised residuals because of the $p$-values that are below 0.05 . It can be concluded that the standardised residuals from the fitted models are nonnormal; hence, asymmetrical models can be fitted under the assumption of STD innovations among others.

Asymmetric models (EGARCH, TGARCH and APARCH) were also fitted to the data. Summarised ARMA $(1,1)$ EGARCH $(1,1)$ model results are displayed in Figure 4.

The model parameters in Figure 4 are all statistically significant at the $1 \%$ level of significance except for $\alpha_{1}$. The $\operatorname{ARMA}(1,1)$-EGARCH $(1,1)$ model under STD innovations is the better one according to AIC and BIC. The parameter $\gamma$ is statistically significant under all the distributions and all the values are above zero implying less impact of bad news on

TABLE 3: Jarque-Bera test on standardised residuals of the $\operatorname{ARMA}(1,1)$ $\operatorname{GARCH}(1,1)$ models.

\begin{tabular}{lcc}
\hline Model & Jarque-Bera test statistics & $\boldsymbol{p}$ \\
\hline ARMA(1,1)-GARCH(1,1) Norm & 7.0651 & 0.0261 \\
ARMA(1,1)-GARCH(1,1) STD & 6.1459 & 0.0423 \\
ARMA(1,1)-GARCH(1,1) GED & 8.6280 & 0.0382 \\
\hline
\end{tabular}

ARMA, autoregressive moving average; $\mathrm{GARCH}$, generalised autoregressive conditional heteroscedasticity; GED, generalised error distribution; ARCH, autoregressive conditional heteroscedasticity

\begin{tabular}{|c|c|c|c|c|c|c|}
\hline $\begin{array}{l}\text { Variables } \\
\text { Mean equation }\end{array}$ & \multicolumn{2}{|c|}{$\begin{array}{c}\operatorname{ARMA}(1,1)-G A R C H(1,1) \\
\text { Norm }\end{array}$} & \multicolumn{2}{|c|}{$\begin{array}{c}\text { ARMA(1,1)-GARCH(1,1) } \\
\text { STD }\end{array}$} & \multicolumn{2}{|c|}{$\underset{\text { ARMA(1,1)-GARCH(1,1) }}{\operatorname{GED}}$} \\
\hline & Estimate & $p$ & Estimate & $p$ & Estimate & $p$ \\
\hline$\phi$ & 0.6418 & $<0.0001$ & 0.7356 & $<0.0001$ & 0.6958 & $<0.0001$ \\
\hline$\theta$ & -0.4328 & 0.0112 & -0.4894 & 0.0001 & -0.4292 & 0.0012 \\
\hline \multicolumn{7}{|l|}{ Variance equation } \\
\hline & Estimate & $p$ & Estimate & $p$ & Estimate & $p$ \\
\hline$\Omega$ & 0.0211 & 0.0003 & 0.0245 & 0.0113 & 0.0226 & 0.0039 \\
\hline$\alpha_{1}$ & 0.5200 & 0.0002 & 0.6639 & 0.0082 & 0.5601 & 0.0038 \\
\hline$\beta_{1}$ & 0.3131 & 0.0008 & 0.2581 & 0.0300 & 0.2876 & 0.0246 \\
\hline \multicolumn{7}{|l|}{ Goodness of fit } \\
\hline AIC & \multicolumn{2}{|c|}{0.3204} & \multicolumn{2}{|c|}{0.2769} & \multicolumn{2}{|c|}{0.2804} \\
\hline $\mathrm{BIC}$ & \multicolumn{2}{|c|}{0.4160} & \multicolumn{2}{|c|}{0.3885} & \multicolumn{2}{|c|}{0.3920} \\
\hline \multicolumn{7}{|c|}{ Weighted Ljung-Box test on standardised residuals } \\
\hline & Statistic & $p$ & Statistic & $p$ & Statistic & $p$ \\
\hline $\operatorname{Lag}[1]$ & 0.06691 & 0.7959 & 0.06684 & 0.7960 & 0.1818 & 0.6699 \\
\hline $\operatorname{Lag}[2 *(p+q)+(p+q)-1][5]$ & 0.74265 & 1.0000 & 0.40125 & 1.0000 & 0.5845 & 1.0000 \\
\hline $\operatorname{Lag}[4 *(p+q)+(p+q)-1][9]$ & 2.68743 & 0.9323 & 2.61984 & 0.9397 & 2.7766 & 0.9216 \\
\hline \multicolumn{7}{|c|}{ Weighted Ljung-Box test on standardised squared residuals } \\
\hline & Statistic & $p$ & Statistic & $p$ & Statistic & $p$ \\
\hline $\operatorname{Lag}[1]$ & 0.398 & 0.5281 & 0.0037 & 0.9517 & 0.0612 & 0.8046 \\
\hline $\operatorname{Lag}[2 *(p+q)+(p+q)-1][5]$ & 2.084 & 0.5988 & 0.9897 & 0.8620 & 1.2557 & 0.7996 \\
\hline $\operatorname{Lag}[4 *(p+q)+(p+q)-1][9]$ & 3.612 & 0.6552 & 2.3854 & 0.8544 & 2.7468 & 0.7999 \\
\hline \multicolumn{7}{|l|}{ Weighted ARCH LM tests } \\
\hline & Statistic & $p$ & Statistic & $p$ & Statistic & $p$ \\
\hline ARCH Lag[3] & 1.054 & 0.3046 & 0.4844 & 0.4864 & 0.4961 & 0.4812 \\
\hline ARCH Lag[5] & 3.289 & 0.2505 & 2.1812 & 0.4326 & 2.5976 & 0.3537 \\
\hline ARCH Lag[7] & 3.571 & 0.4126 & 2.5098 & 0.6104 & 2.8917 & 0.5342 \\
\hline
\end{tabular}

ARMA, autoregressive moving average; GARCH, generalised autoregressive conditional heteroscedasticity; GED, generalised error distribution; ARCH, autoregressive conditional heteroscedasticity LM, Lagrange Multiplier.

FIGURE 3: ARMA(1,1)-GARCH(1,1) model parameters. 


\begin{tabular}{|c|c|c|c|c|c|c|}
\hline $\begin{array}{l}\text { Variables } \\
\text { Mean equation }\end{array}$ & \multicolumn{2}{|c|}{$\begin{array}{l}\text { ARMA(1,1)-EGARCH(1,1) } \\
\text { Norm }\end{array}$} & \multicolumn{2}{|c|}{$\begin{array}{l}\text { ARMA(1,1)-EGARCH(1,1) } \\
\text { STD }\end{array}$} & \multicolumn{2}{|c|}{$\begin{array}{l}\operatorname{ARMA}(\mathbf{1}, \mathbf{1})-\mathrm{EGARCH}(1,1) \\
\text { GED }\end{array}$} \\
\hline & Estimate & $p$ & Estimate & $p$ & Estimate & $p$ \\
\hline$\phi$ & 0.7088 & $<0.0001$ & 0.7829 & $<0.0001$ & 0.7384 & $<0.0001$ \\
\hline$\theta$ & -0.5410 & $<0.0001$ & -0.5612 & $<0.0001$ & -0.5049 & $<0.0001$ \\
\hline \multicolumn{7}{|l|}{ Variance equation } \\
\hline & Estimate & $p$ & Estimate & $p$ & Estimate & $p$ \\
\hline$\Omega$ & -1.0795 & $<0.0001$ & -1.0763 & 0.0004 & -1.1362 & 0.0002 \\
\hline$\alpha_{1}$ & -0.1481 & 0.1115 & -0.1524 & 0.1745 & -0.1543 & 0.1698 \\
\hline$\beta_{1}$ & 0.5756 & $<0.0001$ & 0.5718 & $<0.0001$ & 0.5625 & $<0.0001$ \\
\hline$\Gamma$ & 0.8385 & $<0.0001$ & 0.9743 & $<0.0001$ & 0.8870 & $<0.0001$ \\
\hline shape & - & - & 4.4477 & 0.0063 & 1.2794 & $<0.0001$ \\
\hline \multicolumn{7}{|l|}{ Goodness of fit } \\
\hline AIC & \multicolumn{2}{|c|}{0.3218} & \multicolumn{2}{|c|}{0.2838} & \multicolumn{2}{|c|}{0.2862} \\
\hline $\mathrm{BIC}$ & \multicolumn{2}{|c|}{0.4334} & \multicolumn{2}{|c|}{0.4113} & \multicolumn{2}{|c|}{0.4137} \\
\hline \multicolumn{7}{|c|}{ Weighted Ljung-Box test on standardised residuals } \\
\hline & Statistic & $p$ & Statistic & $p$ & Statistic & $p$ \\
\hline Lag[1] & 0.5432 & 0.4611 & 0.0078 & 0.9297 & 0.01427 & 0.9049 \\
\hline $\operatorname{Lag}[2 *(p+q)+(p+q)-1][5]$ & 1.7140 & 0.9908 & 0.4220 & 1.0000 & 0.57482 & 1.0000 \\
\hline $\operatorname{Lag}[4 *(p+q)+(p+q)-1][9]$ & 3.8447 & 0.7269 & 2.8360 & 0.9139 & 2.89550 & 0.9058 \\
\hline \multicolumn{7}{|c|}{ Weighted Ljung-Box test on standardised squared residuals } \\
\hline & Statistic & $p$ & Statistic & $p$ & Statistic & $p$ \\
\hline Lag[1] & 0.0065 & 0.9356 & 0.3257 & 0.5682 & 0.09202 & 0.7616 \\
\hline $\operatorname{Lag}[2 *(p+q)+(p+q)-1][5]$ & 2.9044 & 0.4248 & 1.8341 & 0.6581 & 2.31948 & 0.5451 \\
\hline $\operatorname{Lag}\left[4^{*}(p+q)+(p+q)-1\right][9]$ & 4.2523 & 0.5466 & 3.6869 & 0.6423 & 3.98975 & 0.5906 \\
\hline \multicolumn{7}{|l|}{ Weighted ARCH LM tests } \\
\hline & Statistic & $p$ & Statistic & $p$ & Statistic & $p$ \\
\hline ARCH Lag[3] & 3.634 & 0.05661 & 1.728 & 0.1887 & 2.636 & 0.1045 \\
\hline ARCH Lag[5] & 4.237 & 0.15368 & 2.565 & 0.3595 & 3.572 & 0.2168 \\
\hline ARCH Lag[7] & 4.571 & 0.27163 & 3.693 & 0.3930 & 4.249 & 0.3121 \\
\hline
\end{tabular}

ARMA, autoregressive moving average; EGARCH, exponential generalised autoregressive conditional heteroscedasticity; GED, generalised error distribution; ARCH, autoregressive conditional heteroscedasticity; LM, Lagrange Multiplier; AIC, Akaike information criterion; BIC, Bayesian information criterion.

FIGURE 4: ARMA(1,1)-EGARCH(1,1) model parameters.

future tourism volatility when compared to good news of the same size. Bad news, like the information about cholera outbreak in Zimbabwe, will have less effect on tourist arrivals than information about zero cases of terrorism in Zimbabwe. The results are similar to those of Chang, Hsu and McAleer (2014) who obtained insignificant risk premium estimates in Taiwan. According to $\beta$, persistence level is not too high, meaning effect of tourism shocks will not last longer. There is no autocorrelation in the model residuals as supported by the Ljung-Box test statistic values that are associated with the $p$-values of both the squared residuals and standardised squared residuals at all lags (Lag 1, Lag 2 and Lag 4) which are all above 0.05 . The fitted models also indicate no dependencies in the standardised series as indicated by the $\mathrm{ARCH}$ LM test statistic values that are associated with p-values (at Lag 3, Lag 5 and Lag 7) which are all above 0.05 . An ARMA(1,1)-TGARCH(1,1) model was fitted as well and Figure 5 summarises the results.

All the models in Figure 5 passed the white noise test as indicated by the Ljung-Box test statistic values which are associated with large $p$-values of both squared residuals and standardised squared residuals, at all lags (Lag 1, Lag 2 and Lag 4) which are all above 0.05 implying no presence of autocorrelation in the standardised residuals or squared standardised residuals. The ARCH LM test statistic values at
Lag 3, Lag 5 and Lag 7 show no dependencies in the standardised series because of the corresponding $p$-values that are above 0.05 . It can be noted from Figure 5 results that only the parameter $\gamma$ is not statistically significant, but the rest of the parameters are significant. The AIC and BIC indicated the ARMA $(1,1)$-TGARCH $(1,1)$ model under STD as the best model. The impact of the good news coefficient is high (0.5686) for the model under STD innovations when compared to other models, which is a favourable aspect when it comes to tourism as it impacts positively on the industry. The bad news of the same model coefficient $(\alpha+\gamma=$ $0.7585)$ is slightly higher and this will lead to tourism volatility increases because of bad news as $\gamma(=0.1899)$ is above zero. This also shows the existence of leverage effects. This means any unfavourable tourism information like war, economic shrinking, terrorism news and punitive exchange rates will significantly hinder the success of the tourism industry. This will affect international tourists' decision to visit the country and will also limit investors' investing capacity. This adversely affects investment decisions in the tourism industry because of the increasing risk in international tourist arrivals.

Most of the variance equation parameters in Figure 6 are not statistically significant. This is despite the AIC and BIC suggesting that the $\operatorname{ARMA}(1,1)-\operatorname{APARCH}(1,1)$ model under 


\begin{tabular}{|c|c|c|c|c|c|c|}
\hline $\begin{array}{l}\text { Variables } \\
\text { Mean equation }\end{array}$ & \multicolumn{2}{|c|}{$\begin{array}{c}\operatorname{ARMA}(\mathbf{1}, \mathbf{1})-\mathrm{TGARCH}(1,1) \\
\text { Norm }\end{array}$} & \multicolumn{2}{|c|}{$\begin{array}{c}\text { ARMA(1,1)-TGARCH(1,1) } \\
\text { STD }\end{array}$} & \multicolumn{2}{|c|}{ 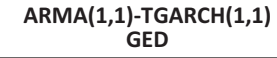 } \\
\hline & Estimate & $p$ & Estimate & $p$ & Estimate & $p$ \\
\hline$\phi$ & 0.6630 & $<0.0001$ & 0.7358 & $<0.0001$ & 0.7041 & $<0.0001$ \\
\hline$\theta$ & -0.4648 & 0.0074 & -0.4960 & 0.0001 & -0.4394 & 0.0014 \\
\hline \multicolumn{7}{|l|}{ Variance equation } \\
\hline & Estimate & $p$ & Estimate & $p$ & Estimate & $p$ \\
\hline$\Omega$ & 0.0221 & 0.0004 & 0.0244 & 0.0110 & 0.0230 & 0.0047 \\
\hline$\alpha_{1}$ & 0.3821 & 0.0155 & 0.5686 & 0.0343 & 0.4425 & 0.0309 \\
\hline$\beta_{1}$ & 0.3017 & 0.0017 & 0.2510 & 0.0349 & 0.2764 & 0.0313 \\
\hline$\Gamma$ & 0.2423 & 0.2982 & 0.1899 & 0.5844 & 0.2378 & 0.4353 \\
\hline shape & & & 4.4965 & 0.0086 & 1.2679 & $<0.0001$ \\
\hline \multicolumn{7}{|l|}{ Goodness of fit } \\
\hline AIC & \multicolumn{2}{|c|}{0.3247} & \multicolumn{2}{|c|}{0.2850} & \multicolumn{2}{|c|}{0.2867} \\
\hline $\mathrm{BIC}$ & \multicolumn{2}{|c|}{0.4363} & \multicolumn{2}{|c|}{0.4125} & \multicolumn{2}{|c|}{0.4142} \\
\hline \multicolumn{7}{|c|}{ Weighted Ljung-Box test on standardised residuals } \\
\hline & Statistic & $p$ & Statistic & $p$ & Statistic & $p$ \\
\hline $\operatorname{Lag}[1]$ & 0.1186 & 0.7305 & 0.05108 & 0.8212 & 0.2231 & 0.6367 \\
\hline $\operatorname{Lag}[2 *(p+q)+(p+q)-1][5]$ & 0.9049 & 1.0000 & 0.45474 & 1.0000 & 0.7162 & 1.0000 \\
\hline $\operatorname{Lag}[4 *(p+q)+(p+q)-1][9]$ & 2.8182 & 0.9163 & 2.59854 & 0.9420 & 2.8681 & 0.9096 \\
\hline \multicolumn{7}{|c|}{ Weighted Ljung-Box test on standardised squared residuals } \\
\hline & Statistic & $p$ & Statistic & $p$ & Statistic & $p$ \\
\hline $\operatorname{Lag}[1]$ & 0.2593 & 0.6106 & 0.00263 & 0.9591 & 0.01134 & 0.9152 \\
\hline $\operatorname{Lag}[2 *(p+q)+(p+q)-1][5]$ & 1.6514 & 0.7027 & 0.90510 & 0.8808 & 0.97895 & 0.8644 \\
\hline $\operatorname{Lag}[4 *(p+q)+(p+q)-1][9]$ & 3.1640 & 0.7316 & 2.25183 & 0.8729 & 2.41644 & 0.8499 \\
\hline \multicolumn{7}{|l|}{ Weighted ARCH LM tests } \\
\hline & Statistic & $p$ & Statistic & $p$ & Statistic & $p$ \\
\hline ARCH Lag[3] & 1.073 & 0.3004 & 0.5146 & 0.4732 & 0.4871 & 0.4852 \\
\hline ARCH Lag[5] & 2.708 & 0.3350 & 2.0803 & 0.4538 & 2.2152 & 0.4256 \\
\hline ARCH Lag[7] & 3.201 & 0.4763 & 2.4048 & 0.6321 & 2.5720 & 0.5977 \\
\hline
\end{tabular}

ARMA, autoregressive moving average; TGARCH, threshold generalised autoregressive conditional heteroscedasticity; GED, generalised error distribution; ARCH, autoregressive conditional heteroscedasticity; LM, Lagrange Multiplier; AIC, Akaike information criterion; BIC, Bayesian information criterion.

FIGURE 5: $\operatorname{ARMA}(1,1)-\operatorname{TGARCH}(1,1)$ model.

GED innovations as the better model. This model is therefore not usable despite the fact that the model passed the white noise test as indicated by the Ljung-Box test statistic values which are associated with the $p$-values of both the squared residuals and standardised squared residuals at all lags (Lag 1, Lag 2 and Lag 4) which are all above 0.05 indicating the absence of autocorrelation into the model residuals. The ARCH LM test statistic values of the models at Lag 3, Lag 5 and Lag 7 show no dependencies in the standardised series because of the corresponding $p$-values that are above 0.05 .

From the symmetric models, the AIC and BIC criteria suggest an ARMA(1,1)-GARCH(1,1) model under STD innovations (Figure 3 ) as the best model in terms of performance. The ARMA(1,1)-EGARCH(1,1) model under STD innovations (Figure 4) best fits the volatility of Zimbabwe's tourism arrivals according to the AIC and BIC values. The model indicated the presence of statistically significant asymmetric effects $(\gamma=0.9743)$; hence, negative tourism shocks will have a more moderate impact on international tourist arrivals than positive tourism shocks. This is good news to tourism stakeholders and investors as they can invest with less volatility risk. Persistence of shocks $\left(\beta_{1}=0.5718\right)$ is not too high implying that tourism shocks like economic and political instability will not last long and hence will not impact heavily on international tourist arrivals. This should motivate foreign tourism investors to invest in the Zimbabwe tourism industry.

\section{Conclusions}

Many developing countries, including Zimbabwe, are affected by sudden international tourist arrivals' fluctuations. To capture the nature of the volatility, it is vital for countries like Zimbabwe to adopt symmetric and asymmetric tourism volatility models in modelling international tourism volatility. The methods are capable of producing accurate and informative volatility forecasts for decision-making processes. For this study, the symmetric model indicated that unexpected tourism shocks have a strong impact that persists for a significant period of time on Zimbabwe's tourist arrivals. The asymmetric model indicated that there is less impact of bad news on future tourism volatility when compared to good news of the same size. This indicates the need of strong measures like new tourism marketing strategies to deal with the persisting effect of tourism shocks.

The tourism industry in Zimbabwe has the potential of contributing significantly to the country's economy although not in isolation. The responsible tourism authorities may resort to this novel forecasting approach which can act as a breeding ground of effective and efficient tourism revival polices. International tourists are the main source of export receipts for various countries, including Zimbabwe; hence, proper management of the industry will significantly improve residents' livelihoods through foreign currency earnings and tourism receipts generated from the industry. 


\begin{tabular}{|c|c|c|c|c|c|c|}
\hline Mean equation & \multicolumn{2}{|c|}{$\begin{array}{l}\text { ARMA(1,1)-APARCH(1,1) } \\
\text { Norm }\end{array}$} & \multicolumn{2}{|c|}{$\begin{array}{l}\operatorname{ARMA}(1,1)-\operatorname{APARCH}(1,1) \\
\text { STD }\end{array}$} & \multicolumn{2}{|c|}{$\begin{array}{l}\operatorname{ARMA}(1,1)-\operatorname{APARCH}(1,1) \\
\text { GED }\end{array}$} \\
\hline & Estimate & $p$ & Estimate & $p$ & Estimate & $p$ \\
\hline$\phi$ & 0.6631 & $<0.0001$ & 0.7280 & $<0.0001$ & 0.6996 & $<0.0001$ \\
\hline$\theta$ & -0.4620 & 0.0074 & -0.4892 & 0.0001 & -0.4417 & 0.0001 \\
\hline \multicolumn{7}{|l|}{ Variance equation } \\
\hline & Estimate & $p$ & Estimate & $p$ & Estimate & $p$ \\
\hline$\Omega$ & 0.0044 & 0.0004 & 0.0133 & 0.6230 & 0.0089 & 0.6269 \\
\hline$\alpha_{1}$ & 0.4276 & 0.0155 & 0.5855 & 0.0082 & 0.5081 & 0.0171 \\
\hline$\beta_{1}$ & 0.2613 & 0.0017 & 0.2446 & 0.0559 & 0.2558 & 0.0744 \\
\hline$\gamma$ & 0.0746 & 0.2982 & 0.0604 & 0.6388 & 0.0801 & 0.5380 \\
\hline$\delta$ & 3.1057 & 2.3926 & 2.3926 & 0.0633 & 2.6444 & 0.0496 \\
\hline shape & - & 5.1313 & 5.1313 & 0.0166 & 1.3109 & $<0.0001$ \\
\hline \multicolumn{7}{|l|}{ Goodness of fit } \\
\hline AIC & \multicolumn{2}{|c|}{0.3219} & \multicolumn{2}{|c|}{0.2919} & \multicolumn{2}{|c|}{0.2918} \\
\hline $\mathrm{BIC}$ & \multicolumn{2}{|c|}{0.4449} & \multicolumn{2}{|c|}{0.4353} & \multicolumn{2}{|c|}{0.4353} \\
\hline \multicolumn{7}{|c|}{ Weighted Ljung-Box test on standardised residuals } \\
\hline & Statistic & $p$ & Statistic & $p$ & Statistic & $p$ \\
\hline $\operatorname{Lag}[1]$ & 0.1369 & 0.7114 & 0.03301 & 0.8558 & 0.1373 & 0.7110 \\
\hline $\operatorname{Lag}\left[2^{*}(p+q)+(p+q)-1\right][5]$ & 0.8402 & 1.0000 & 0.43307 & 1.0000 & 0.6212 & 1.0000 \\
\hline $\operatorname{Lag}\left[4^{*}(p+q)+(p+q)-1\right][9]$ & 2.8656 & 0.9100 & 2.64923 & 0.9365 & 2.8647 & 0.9101 \\
\hline \multicolumn{7}{|c|}{ Weighted Ljung-Box test on standardised squared residuals } \\
\hline & Statistic & $p$ & Statistic & $p$ & Statistic & $p$ \\
\hline Lag[1] & 0.3173 & 0.5733 & 0.0018 & 0.9662 & 0.02176 & 0.8827 \\
\hline $\operatorname{Lag}[2 *(p+q)+(p+q)-1][5]$ & 1.5796 & 0.7203 & 0.9200 & 0.8775 & 0.95861 & 0.8690 \\
\hline $\operatorname{Lag}\left[4^{*}(p+q)+(p+q)-1\right][9]$ & 3.1366 & 0.7362 & 2.3062 & 0.8655 & 2.42777 & 0.8483 \\
\hline \multicolumn{7}{|l|}{ Weighted ARCH LM tests } \\
\hline & Statistic & $p$ & Statistic & $p$ & Statistic & $p$ \\
\hline ARCH Lag[3] & 0.7063 & 0.4007 & 0.4258 & 0.5140 & 0.3373 & 0.5614 \\
\hline ARCH Lag[5] & 2.6081 & 0.3519 & 2.1343 & 0.4423 & 2.2047 & 0.4277 \\
\hline ARCH Lag[7] & 3.0247 & 0.5089 & 2.4425 & 0.6243 & 2.5357 & 0.6051 \\
\hline
\end{tabular}

ARMA, autoregressive moving average; TGARCH, threshold generalised autoregressive conditional heteroscedasticity; GED, generalised error distribution; ARCH, autoregressive conditional heteroscedasticity; LM, Lagrange Multiplier; AIC, Akaike information criterion; BIC, Bayesian information criterion.

FIGURE 6: $\operatorname{ARMA}(1,1)-\operatorname{APARCH}(1,1)$ model.

Zimbabwe as a country needs to manage itself properly out of the negative publicity in the media by various media organisations. This negative media can adversely affect the tourism industry. The positive offensive can start with our own politicians avoiding being in the news for the wrong reasons. Examining the behaviour of both the international tourist arrivals and volatility is crucial for managers as this will help in crafting marketing strategies that will clear the bad name of the country to old, new and emerging tourism markets. International tourist arrivals' volatility can be referred to as the risk associated with international tourist arrivals. It is a risk that needs careful handling and management.

Both the ARMA(1,1)-GARCH(1,1) and ARMA(1,1)EGARCH $(1,1)$ models under $t$-distribution (STD) innovations are a good fit for international tourist arrivals in Zimbabwe. Considering the ARMA $(1,1)-\mathrm{GARCH}(1,1)$ model, it is able to capture the dynamics in the tourism industry. However, it will be difficult to formulate specific policies in Zimbabwe because the model does not give theoretical explanation of the major tourism volatility determinants. As for the $\operatorname{ARMA}(1,1)-E G A R C H(1,1)$ model, effective and efficient short- and long-run polices can be implemented because the model captures volatility and leverage effects. However, uncertainty in Zimbabwe's tourism sector because of various factors like political instability may hinder the success of the adoption of the model.

It will be prudent to extend the modelling of international tourist arrivals to source markets if the data are readily available. This will help in coming up with best marketing strategies for each source market.

\section{Acknowledgements}

The authors would like to acknowledge the Zimbabwe Tourism Authority (ZTA) which assisted with the data for the research.

\section{Competing interests}

The authors declare that they have no financial or personal relationships that may have inappropriately influenced them in writing this article.

\section{Authors' contributions}

D.C. came up with the ideas of the article, did the initial draft and proofread the article. T.M. analysed the data and completed the writing of the article. 


\section{Ethical consideration}

The authors sought permission of using secondary tourist arrivals data from the Zimbabwe Tourism Authority (ZTA).

\section{Funding}

This research received no specific grant from any funding agency in the public, commercial or not-for-profit sectors.

\section{Data availability statement}

Data sharing is not applicable to this article as no new data were created or analysed in this study.

\section{Disclaimer}

The views and opinions expressed in this article are those of the authors and do not necessarily reflect the official policy or position of any affiliated agency of the authors.

\section{References}

Adhikari, R. \& Agrawal, R.K., 2013, 'An introductory study on time series modelling and forecasting', arXiv Preprint 1302, 6613.

Alberg, D., Shalit, H. \& Yosef, R., 2008, 'Estimating stock market volatility using asymmetric GARCH models', Applied Financial Economics 18(15), 1201-1208. https://doi.org/10.1080/09603100701604225

Angabini, A. \& Wasiuzzaman, S., 2011, 'Impact of the global financial crisis on the volatility of the Malaysian stock market', 2010 International Conference on E-business, Management and Economics 3(1), 79-84.

Basera, V., 2018, 'Tourism marketing strategies and domestic tourism demand in Kariba resort (Zimbabwe)', Journal of Tourism and Hospitality 7, 344. https://doi. org/10.4172/2167-0269.1000344.

Bollerslev, T. 1986, 'Generalized autoregressive conditional heteroskedasticity', Journa of Econometrics 31(3), 307-327. https://doi.org/10.1016/0304-4076(86)90063-1

Bollerslev, T., 1987, 'A conditionally heteroskedastic time series model for speculative prices and rates of return', The Review of Econometrics and Statistics 69(3), 542-547. https://www.jstor.org/stable/1925546

Chang, C. \& McAleer, M., 2009, 'Daily tourist arrivals, exchange rates and volatility for Korea and Taiwan', Korean Economic Review 25(2), 241-267. https://doi.org/ $10.2139 /$ ssrn.1504651

Chang, C., Hsu, H. \& McAleer, M., 2014, 'The impact of China on stock returns and volatility in the Taiwan tourism industry', The North American Journal of Economics and Finance 29(1), 381-401. https://doi.org/10.1016/j.najef.2014.06.007

Chang, C.L., McAleer, M. \& Slottje, D.J., 2009, 'Modelling international tourist arrivals and volatility: An application to Taiwan', in B.H. Baltagi, E. Sadka (series eds.) \& D. Slottje (vol. ed.), Contributions to economic analysis: Quantifying consumer preferences, vol. 288, no. 11, pp. 299-315, Emerald Group Publishing, Bingley, UK, preferences, vol. 288, no. 11, pp. 299-315, Emerald Group Publish
viewed from https://core.ac.uk/download/pdf/19711929.pdf.

Chhorn, T. \& Chaiboonsri, C., 2018, 'Modelling and forecasting tourist arrivals to Cambodia: An application of ARIMA-GARCH approach', Journal of Management, Economics, and Industrial Organization 2(2), 1-19. https://doi.org/10.31039/jomeino.2018.2.2.1

Divino, J.A. \& McAleer, M., 2009, 'Modelling the growth and volatility in daily international mass tourism to Peru, viewed 10 November 2018, from https://pdfs. semanticscholar.org/58c2/060209a785cb01cec770916e61875ec77344.pdf.

Ding, Z., C. Granger, C.W. \& Engle, R.F., 1993, 'A long memory property of stock marke returns and a new model', Journal of Empirical Finance 1(1), 83-106. https://doi. org/10.1016/0927-5398(93)90006-D

Engle, R.F., 1982, 'Autoregressive conditional heteroscedasticity with estimates of the variance of United Kingdom inflation', Econometrica 50(4), 987-1007. https://doi. org/10.2307/1912773

Engle, R.F., Focardi, S.M. \& Fabozzi, F.J., 2012, 'ARCH/GARCH models in applied financial econometrics', Encyclopedia of Financial Models, viewed 30 October 2018, from https://onlinelibrary.wiley.com/doi.org/10.1002/9781118182635.efm0062.

Fernando, S., 2016, 'Tourism demand, volatility and post-war tourism in Sri Lanka', University of Kelaniya, Sri Lanka, viewed 02 November 2018, from: https://www. academia.edu/33979165/Tourism_demand_volatility_and_the_post-war tourism_in_Sri_Lanka.
Fernando, S., Bandara, J.S., Liyanaarachch, S., Jayathilaka, R. \& Smith, C., 2013, 'Political violence and volatility in international tourist arrivals: The case of Sri Lanka', Tourism Analysis 18(5), 575-586. https://doi.org/10.3727/10835421 3X13782245307876

Glosten, L.R., Jagannathan, R. \& Runkle, D.E., 1993, 'On the relation between the expected value and the volatility of the nominal excess return on stocks', The Journal of Finance 48(5), 1779-1801. https://doi.org/10.1111/j.1540-6261.1993.tb05128.x

Hoti, S., Leon, C.J. \& McAleer, M., 2004, International tourism demand and volatility models for the Canary Islands, International Congress on Environmental Modelling and Software, June 2004, viewed 16 November 2018, from https://scholarsarchive. byu.edu/iemssconference/2004/all/113.

Jegajeevan, S., 2012, 'Return volatility and asymmetric news effect in Sri Lankan stock market', Staff Studies 40(1), 37-57. https://doi.org/10.4038/ss.v40i1.4680

Kabote, F., Mashiri, B. \& Vengesayi, S., 2014, 'Pricing and domestic tourism performance in Zimbabwe', African Journal of Hospitality, Tourism and Leisure 3(2), 1-12.

Karlsson, L., 2002, GARCH modelling, Algorithmica Research AB, Stockholm.

Kelly, S., 2016, 'Zimbabwe offering amazing diversity and hospitality', viewed 10 August 2018, from http://www.zimbabweconnections.com/wp-content/uploads/2016/08/ Zimbabwean-Tourism-July-2016.pdf.

Lama, A., Jhab, G.K., Paula, R.K. \& Gurunga, B., 2015, 'Modelling and forecasting of price volatility: An application of GARCH and EGARCH models', Agricultural Economics Research Review 28(1), 73-82. https://doi.org/10.5958/0974-0279. Economics Resed 2015.00005 .1

Ling, S. \& McAleer, M., 2002, 'Necessary and sufficient moment conditions for the GARCH $(r, s)$ and asymmetric power GARCH $(r, s)$ models', Econometric Theory 18(3), 722-729. https://doi.org/10.1017/S0266466602183071

Lorde, T. \& Moore, W., 2008, 'Modelling and forecasting the volatility of long-stay tourist arrivals', Tourism Analysis 13(1), 43-51. https://doi.org/10.3727/1083 54208784548742

McAleer, M., Chan, F. \& Marinova, D, 2007, 'An econometric analysis of asymmetric volatility: Theory and application to patents', Journal of Econometrics 139(2), 259-284. https://doi.org/10.1016/j.jeconom.2006.10.014

Muchapondwa, E. \& Pimhidzai, O., 2011, 'Modelling international tourism demand for Zimbabwe', International Journal of Business and Social Science 2(2), 71-81.

Mutsena, C. \& Kabote, F., 2015, 'Zimbabwe policy environment and domestic tourism performance', International Journal of Safety and Security in Tourism and Hospitality 1(13), 1.

Nelson, D.B., 1991, 'Conditional heteroskedasticity in asset returns: A new approach', Econometrica: Journal of the Econometric Society 59(2), 347-370. https://doi. org/10.2307/2938260

Neumayer, E., 2004, 'The impact of political violence on tourism', Journal of Conflict Resolution 48(2), 259-281. https://doi.org/10.1177/0022002703262358

Neupane, H.S., Shrestha, C.L. \& Upadhyaya, T.P., 2012, 'Modelling monthly international tourist arrivals and its risk in Nepal', NRB Economic Review 24(1), 28-47.

Ogutu, C., Canhanga, B. \& Biganda, P. 2018, 'Modeling exchange rate volatility using APARCH models', Journal of the Institute of Engineering 14(1), 96-106. https:// doi.org/10.3126/jie.v14i1.20072

Omari, C.O., Mwita, P.N. \& Waititu, A.G., 2017, 'Modelling USD/KES exchange rate volatility using GARCH models', IOSR Journal of Economics and Finance (IOSR-JEF) 8(1), 15-26. https://doi.org/10.9790/5933-0801011526

Page, S. \& Lumsdon, L., 2004, Tourism and transport: Issues and agenda for new millennium, Elsevier, Boston, MA.

Priyangika, J.H., Pallawala, P.K.B.N.M. \& Sooriyaarachchi, D.J.C., 2016, 'Modelling and forecasting tourist arrivals in Sri Lanka', Symposium on Statistical \& Computational Modelling with Applications (SymSCMA - 2016), Department of Statistics \& Computer Science, University of Kelaniya, Sri Lanka, pp. 14-18, viewed 28 October 2019, from http://repository.kln.ac.lk/handle/123456789/15547.

Rodriguez, G., 2017, 'Selecting between autoregressive conditional heteroskedasticity models: An empirical application to the volatility of stock returns in Peru', Revisto de Análisis Económico 32(1), 69-94. https://doi.org/10.4067/S0718-887020170 00100069

Shareef, R. \& McAleer, M., 2015, 'Modelling international tourism demand and volatility in small island tourism economies', International Journal of Tourism Research 7(6), 313-333. https://doi.org/10.1002/jtr.538

Tsay, R.S., 2010, Analysis of financial time series, 3rd edn., John Wiley \& Sons, viewed 01 November 2018, from http://www.Ics.poli.usp.br/ ablima/livros/Analysis\%20 of $\% 20$ financial $\% 20$ time $\% 20$ series $\% 20$ Tsay.pdf.

Zakoian, J., 1994, 'Threshold heteroskedastic models', Journal of Economic Dynamics and Control 18(5), 931-955. https://doi.org/10.1016/0165-1889(94)90039-6

Zimbabwe Parks and Wildlife Management Authority, 2017, Government of Zimbabwe, Printflow, Harare, viewed 10 November 2018, from http://zimparks. org/wp-content/uploads/2015/10/Zimparks-Prospectus-Website.pdf. 